\title{
The Factors Associated with the Attitudes of Nurses Working in Medical Facilities towards Family Nursing
}

\author{
Motoko Hori $^{1}$, Akemi Yamazaki ${ }^{(0)}$, Akemi Soeda ${ }^{3}$, Kazumi Odatsu ${ }^{4}$, Momoko Buyo $^{5}$, \\ Miyuki Matumoto6, Rie Tokutani ${ }^{7}$, Hiroko Mine ${ }^{8}$, Akemi Tsumura ${ }^{9}$, Chisato Kimura ${ }^{10}$, \\ Yuichi Nakayama2,11
}

\author{
${ }^{1}$ Faculty of Nursing, Senrikinran University, Osaka, Japan \\ ${ }^{2}$ Division of Health Sciences, Osaka University Graduate School of Medicine, Osaka, Japan \\ ${ }^{3}$ Bungoohno City Hospital, Oita, Japan \\ ${ }^{4}$ Oita Red Cross Hospital, Oita, Japan \\ ${ }^{5}$ Career Development Center for Nursing, Wakayama Medical University, Wakayama, Japan \\ ${ }^{6}$ Kishiwada Tokushukai Hospital, Osaka, Japan \\ ${ }^{7}$ Otsu Red Cross Hospital, Shiga, Japan \\ ${ }^{8}$ Osaka City General Hospital, Osaka, Japan \\ ${ }^{9}$ Shizuoka Cancer Center, Shizuoka, Japan \\ ${ }^{10}$ Faculty of Health Sciences, Tokyo Metropolitan University, Tokyo, Japan \\ ${ }^{11}$ Faculty of Nursing, Setsunan University, Osaka, Japan \\ Email: akemiyamazaki@sahs.med.osaka-u.ac.jp
}

How to cite this paper: Hori, M., Yamazaki, A., Soeda, A., Odatsu, K., Buyo, M., Matumoto, M., Tokutani, R., Mine, H., Tsumura, A., Kimura, C. and Nakayama, Y. (2020) The Factors Associated with the Attitudes of Nurses Working in Medical Facilities towards Family Nursing. Open Journal of Nursing, 10, 171-183. https://doi.org/10.4236/oin.2020.102011

Received: December 22, 2019

Accepted: February 24, 2020

Published: February 27, 2020

Copyright $\odot 2020$ by author(s) and Scientific Research Publishing Inc. This work is licensed under the Creative Commons Attribution International License (CC BY 4.0).

http://creativecommons.org/licenses/by/4.0/ (c) (i) Open Access

\begin{abstract}
The aim of this study was to clarify the attitudes of nurses working in medical facilities towards family nursing and the related factors. A quantitative cross-sectional design was used. The study period was from December 2017 to February 2018. 638 nurses with more than 5 years clinical experience were recruited from seven medical facilities. The questionnaire included the Families' Importance in Nursing Care-Nurses' Attitudes (FINC-NA), the Family Sense of Coherence (FSOC), and items on nursing practice ability, job satisfaction, and background characteristics. A multiple regression analysis with FINC-NA as the dependent variable and a path analysis of nursing practice ability as the dependent variable were performed. Responses from 416 nurses (effective response rate, 65.2\%) were analyzed. Variables that were significantly related to FINC-NA ( $p<0.05)$ were nursing practice ability, FSOC, job satisfaction, family nursing learning experience, presence of a partner and experience in family nursing. Multiple regression analysis with FINC-NA as the dependent variable revealed significant regression coefficients for nursing practice ability, FSOC and job satisfaction. Moreover, path analysis with
\end{abstract}


nursing practice ability as the dependent variable showed job satisfaction, FSOC, managerial experience, family nursing learning experience were significant. In addition, it was revealed that the direct effect of FSOC on FINC-NA to mediate nursing practice ability was higher than the indirect effect, but the direct effect of job satisfaction on FINC-NA was lower than the indirect effect. It was suggested that it is important that nurses recognize their own thoughts, behaviors and ways of coping with stress within their family, and establish a good work environment and strive to enhance their nursing practice ability.

\section{Keywords}

Family Nursing, Attitude, Stress, Nursing Practice Ability

\section{Introduction}

In nursing care, it is important to support both patients and their family members. To provide continued and high-quality service, nurses need to evaluate whether their own care is effective in enhancing the patient's family's self-care function. There are several available instruments to measure nursing practice abilities, nurses' beliefs, and nurses' attitudes in the field of family nursing, many of which have been developed with a specific area focus, for example, the Family Nurse Caring Belief Scale for nurses working in the Pediatric Intensive Care Unit/Neonatal Intensive Care Unit (NICU) [1], the Family Nursing Practice Scale in Psychiatry [2], and a measure of emergency nurses' attitudes towards family members who have experienced consultation with a patient because of injury or illness, or sudden death [3].

Through the evaluation of family nursing practice and family nursing training, it has been reported that the system and environment of nursing facilities [4] [5], the acquisition of family nursing knowledge and skills [6] [7] [8], the caring experience of nurses' own family [9] [10] [11], and the capacity to establish human relationships [12] affected nursing care for patients' families. Among these related factors, the effect of the acquisition of knowledge and skills has been investigated in numerous studies. However, there have been few studies on nurses' work environment or their individual background characteristics, and some of these previous findings have been inconsistent [13] [14]. On the other hand, there are many studies on relationship between life events or stress and nursing practice [15] [16] [17].

In previous studies on nurses' attitude toward, which is one of the criteria for evaluating family nursing, the relationship between the working environment and individual characteristics of nurses has been reported. Fisher [18] developed a scale of 18 items that evaluate the attitudes and behaviors of nurses in their daily care, and showed that nurses who regarded the presence of family as important were more involved in daily care; however, no other studies have used 
this scale, so the results have yet to be confirmed. Benzein et al. [19] developed the FINC-NA to measure nurses' attitudes towards the importance of involving family in nursing care. The FINC-NA scale has been used in several countries in addition to Sweden where it was developed, and nurses' attitudes toward families in various countries are gradually becoming more clear [20] [21] [22] [23] [24]. Exploring the factors affecting FINC-NA, which is a reliable measure, is expected to help clarify the factors related to family nursing attitudes. Furthermore, to provide more effective family support, we believe that it is important to approach nurses from various perspectives.

\section{Conceptual Framework}

The conceptual framework of this study is shown in Figure 1. Nurses play a role as professionals, employees, and members of their families. We believe that the knowledge, experiences, and feelings gained from each of these roles are correlated with each other and represent facility, professional, and individual factors that affect family nursing attitudes.

\section{Methods}

\subsection{Aim}

The aim of this study was to clarify the attitudes of nurses working in medical facilities towards family nursing and the related factors.

\subsection{Design and Sample}

A quantitative cross-sectional design was used. Participants were recruited from seven medical facilities that agreed to cooperate in the study. The inclusion criteria were nurses with more than 5 years of clinical experience. The exclusion

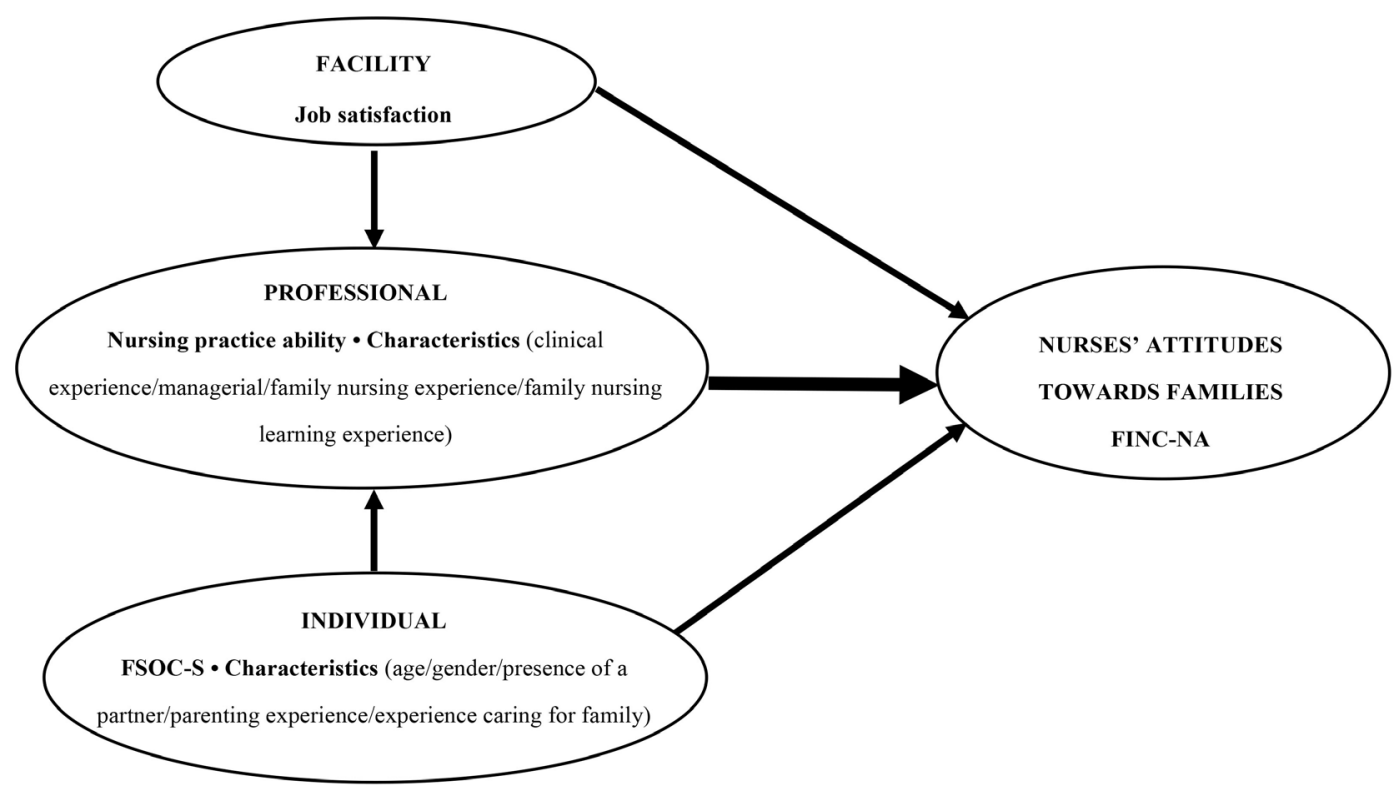

Figure 1. Conceptual framework. 
criteria were nurses who were in a managerial position; on maternity leave, childcare leave, or nursing care leave; or could not read or write Japanese.

\subsection{Data Collection}

Self-administered questionnaires were mailed in December 2017 and the data collection period was from January to February 2018. We asked the representatives of the seven facilities who agreed to cooperate with the research to select participants who met the inclusion criterion, and to distribute and collect the questionnaires. The participants from one facility were all professional nurses and certified nurses who learned family nursing systematically, and participants from another facility were midwives and nurses working in the Department of Obstetrics and Gynecology or NICU. Participants from the other five facilities were nurses working in various departments.

\subsection{Ethical Considerations}

This study was approved by the ethics committee of the authors' institution. The participants were informed that the questionnaires were anonymous and that they could not be identified based on their responses or if they dropped out. Furthermore, it was clarified in writing that there would be no disadvantage if they chose not to participate or if they left blank answers in the questionnaire.

\subsection{Measures}

Demographic characteristics of participants consisted of gender, age, number of years of clinical experiences, number of years in current department, managerial experience, family nursing experience, number of years of family nursing experience, presence of a partner, parenting experience, experience caring for own family, educational background, and family nursing learning experience.

\subsubsection{Nurses' Attitudes towards Families}

FINC-NA was used to evaluate nurses' attitudes towards families. FINC-NA consists of 26 items in the following four subscales: "family as a resource in nursing care" (Fam-RNC), "family as a conversational partner" (Fam-CP), "family as a burden" (Fam-B), and "family as its own resource" (Fam-OR). Responses are provided on a 5-point Likert scale (strongly agree, agree, neutral, disagree and strongly disagree) with total ranging from 26 to 130. The higher the score, the more supportive the nurse's attitude towards families. For the total score of the Japanese version, Cronbach's $\alpha$ for internal consistency was 0.88 and the interclass the correlation coefficient was 0.72 [25].

\subsubsection{Nursing Practice Abilities}

Version 3 of Sato's [26] Clinical Practice Proficiency Measurement Scale for Mid-career Nurses was used to measure clinical practice proficiency. The scale is composed of 21 items in the following four subscales: "ability to contribute to a development of the nursing team," "ability to provide quality care," "ability to 
encourage patient participation in medical care," and "voluntary involvement in current circumstances". Total scores range from 21 to 105, and nurses with more than 67 points are evaluated as mid-career nurses. The higher the score, the higher the self-evaluation in nursing practice abilities. Cronbach's $\alpha$ for items comprising the four subscales was from 0.71 to 0.87 and construct validity was confirmed for all items. Because of the high reliability and validity, this scale has been used in many studies.

\subsubsection{Job Satisfaction}

As a result of reviewing the Japanese literature on job satisfaction among nurses, we found the following five aspect of job satisfaction to be important: "worthwhile job duties", "human relationships", "benefits and work shift", "opportunities for career advancement", and "significance of one's existence". Therefore, we developed a five-item questionnaire. The five items were as follows: "Do you feel your work is worthwhile?", "Are you creating good relationships at work?", "Are you satisfied with the benefits and work shift?", "Are you ensured learning and growth opportunities, such as study meetings or academic conferences?" and "Do you feel you make a significant contribution at work?" Total scores range from 5 to 25 and the higher the score, the higher the job satisfaction.

\subsubsection{FSOC}

The FSOC is used to measure nurses' feelings or behaviors towards their own families. The concept of sense of coherence (SOC) advocated by Antonovsky [27] is defined as the perception that various events in a person's life are coherent. SOC is composed of the concepts of meaningfulness, manageability, and comprehensibility and FSOC is an adaptation of the concept to families.

The FSOC scale consists of 26 items; however, a short version with 12 items (FSOC-S) with responses provided on a 7-point scale has been developed [28]. Total scores range from 12 to 84 with higher score reflecting better perceptions of the coherence of family. In this study, we used the Japanese Version of the Family Sense of Coherence Scale-short form (J-FSOC-S). Translation and validation of the J-FSOC-S were performed prior to this research [29]. Cronbach's $\alpha$ for internal consistency for the total score was 0.85 . The J-FSOC-S showed good test-retest reliability and the interclass correlation coefficient was 0.77 .

\subsection{Data Analysis}

Descriptive statistics for all variables were calculated. An unpaired $t$-test was used to examine differences in the total FINC-NA score based on gender, managerial experience, family nursing experience, presence of a partner, parenting experience, experience caring for own family, and family nursing learning experience. To measure the strength and direction of the association between the total FINC-NA score and each continuous variable, Pearson's correlation coefficient (nursing practice abilities, job satisfaction, FSOC) and Spearman's rank correlation coefficient (age, number of years of clinical experience, number of 
years in current department) were calculated.

In order to clarify the factors associated with FINC-NA, a multiple regression analysis was conducted. Independent variables were selected by the stepwise method and single regression analysis. Then, the variables that have been reported to be related to FINC-NA in preceding studies were added [9] [10] [14]. Furthermore, to analyze factors that indirectly affect FINC-NA, path analysis of variables was conducted. The collected data were analyzed using IBM SPSS version 24 and the level of statistical significance was set at less than $5 \%$.

\section{Results}

Questionnaires were distributed to 638 nurses from seven medical facilities and 480 nurses responded ( $75.2 \%$ response rate). The divisions in which they were working were as follows: internal medicine, surgery, intensive care unit/high care unit, neonatal intensive care unit/growing care unit, obstetrics and gynecology, pediatrics, psychiatry, emergency, gastrointestinal, orthopedic surgery, cardiovascular, neurosurgery, respiratory, operating room, laboratory, outpatient, nursing department, visiting nursing department, dialysis room, rehabilitation, regional collaboration room. Nurses with less than 5 years of clinical experience who did not fully complete all items for FINC-NA, nursing practice abilities, job satisfaction, and FSOC, and those with more than $20 \%$ of the answers to all questions missing were excluded. Finally, the responses of 416 nurses (valid response rate $65.2 \%$ ) were analyzed.

The participants' characteristics are shown in Table 1 . The mean age of participants was 36.6 (standard deviation $[\mathrm{SD}]=7.7$ ) years, the number of years of clinical experience was 13.5 ( $\mathrm{SD}=7.1$ ) years, and the rate of managerial experience was $15.5 \%$. Approximately half of the participants had built a reproductive family (presence of a partner was 53.6\%, presence of parenting experience was $46.3 \%)$. In addition, the rate of experience of caring for own family was $27.2 \%$.

The total FINC-NA score was $91.1(\mathrm{SD}=10.0)$, and the scores for each subscale were as follows: Fam-RNC was $36.0(\mathrm{SD}=4.0)$, Fam-CP was $27.7(\mathrm{SD}=$ 3.7), Fam-B was $14.1(\mathrm{SD}=2.8)$ and Fam-OR was $13.3(\mathrm{SD}=2.4)$. The total score of Version 3 of the Clinical Practice Proficiency Measurement Scale for Mid-career Nurses was $72.8(\mathrm{SD}=11.2)$, the job satisfaction total score was 16.6 $(\mathrm{SD}=3.5)$ and the FSOC total score was $58.3(\mathrm{SD}=11.6)$.

In the case of univariate analyses of total FINC-NA scores, there was a significant correlation $(\mathrm{p}<0.05)$ between nursing practice ability, FSOC, job satisfaction, family nursing learning experience, presence of partner, and experience of family nursing (Table 2).

The results of the multiple regression analysis with FINC-NA as the dependent variable are shown in Table 3. From the 351 nurses who responded to all variables that were significant by the stepwise method, single regression analysis and in preceding studies [9] [10] [14]. we were excluded the two participants 
Table 1. Participant characteristics $(\mathrm{N}=416)$.

\begin{tabular}{|c|c|c|}
\hline & & Mean \pm SD or $\mathrm{N}(\%)$ \\
\hline \multirow{2}{*}{ Gender $(n=414)$} & Female & $386(93.2)$ \\
\hline & Male & $28(6.8)$ \\
\hline Age (years) $(n=410)$ & & $36.6 \pm 7.7$ \\
\hline Clinical experience (years) $(n=412)$ & & $13.5 \pm 7.1$ \\
\hline \multirow[t]{2}{*}{ Managerial experience $(n=414)$} & Yes & $64(15.5)$ \\
\hline & No & $350(84.5)$ \\
\hline \multirow{2}{*}{ Family nursing experience $(n=369)$} & Yes & $342(92.7)$ \\
\hline & No & $27(7.3)$ \\
\hline \multicolumn{2}{|l|}{ Number of years of family nursing experience $(n=337)$} & $6.4 \pm 4.2$ \\
\hline \multirow[t]{2}{*}{ Presence of a partner $(n=403)$} & Yes & $216(53.6)$ \\
\hline & No & $187(46.4)$ \\
\hline \multirow[t]{2}{*}{ Parenting experience $(\mathrm{n}=404)$} & Yes & $187(46.3)$ \\
\hline & No & $217(53.7)$ \\
\hline \multirow{2}{*}{ Experience caring for own family $(\mathrm{n}=401)$} & Yes & $109(27.2)$ \\
\hline & No & $292(72.8)$ \\
\hline \multirow[t]{6}{*}{ Educational background $(\mathrm{n}=410)$} & Nursing school (2 years) & $41(10.0)$ \\
\hline & Nursing school (3 years) & $226(55.1)$ \\
\hline & College & $23(5.6)$ \\
\hline & University & $86(21.0)$ \\
\hline & Graduate school & $6(1.5)$ \\
\hline & Others & $28(6.8)$ \\
\hline \multirow{2}{*}{ Family nursing learning experience $(\mathrm{n}=409)$} & Yes & $250(61.1)$ \\
\hline & No & $159(38.9)$ \\
\hline
\end{tabular}

SD: standard deviation.

Table 2. Single regression analysis of FINC-NA and study variables $(\mathrm{N}=416)$.

\begin{tabular}{ccccc}
\hline & & $\begin{array}{c}\text { Total FINC-NA score } \\
\text { Mean } \pm \text { SD }\end{array}$ & Test & p-value \\
\hline Age $(\mathrm{n}=410)$ & & & $0.051^{\mathrm{a})}$ & 0.302 \\
Gender $(\mathrm{n}=414)$ & Female & $91.3 \pm 10.0$ & & \\
& Male & $88.5 \pm 10.4$ & $1.468^{\mathrm{b})}$ & 0.143 \\
Clinical experience $(\mathrm{n}=412)$ & & & $0.053^{\mathrm{a})}$ & 0.283 \\
Current department $(\mathrm{n}=399)$ & & $-0.001^{\mathrm{a})}$ & 0.977 \\
Managerial experience $(\mathrm{n}=414)$ & Yes & $92.1 \pm 9.3$ & & \\
& No & $91.0 \pm 10.2$ & $0.834^{\mathrm{b})}$ & 0.405 \\
Family nursing experience & Yes & $91.5 \pm 9.5$ & & \\
$(\mathrm{n}=369)$ & No & $87.6 \pm 10.3$ & $2.051^{\mathrm{b})}$ & 0.041 \\
\hline
\end{tabular}




\section{Continued}

\begin{tabular}{|c|c|c|c|c|}
\hline $\begin{array}{l}\text { Presence of a partner } \\
\qquad(\mathrm{n}=403)\end{array}$ & $\begin{array}{l}\text { Yes } \\
\text { No }\end{array}$ & $\begin{array}{l}92.1 \pm 9.7 \\
90.0 \pm 10.2\end{array}$ & $2.122^{\mathrm{b})}$ & 0.034 \\
\hline $\begin{array}{l}\text { Parenting experience } \\
\qquad(\mathrm{n}=404)\end{array}$ & $\begin{array}{l}\text { Yes } \\
\text { No }\end{array}$ & $\begin{array}{l}91.4 \pm 9.4 \\
90.7 \pm 10.5\end{array}$ & $0.705^{\mathrm{b})}$ & 0.481 \\
\hline $\begin{array}{l}\text { Experience caring for own } \\
\text { family }(\mathrm{n}=404)\end{array}$ & $\begin{array}{l}\text { Yes } \\
\text { No }\end{array}$ & $\begin{array}{l}91.8 \pm 10.4 \\
90.7 \pm 9.9\end{array}$ & $1.010^{\mathrm{b})}$ & 0.313 \\
\hline $\begin{array}{l}\text { Family nursing learning } \\
\text { experience }(\mathrm{n}=409)\end{array}$ & $\begin{array}{l}\text { Yes } \\
\text { No }\end{array}$ & $\begin{array}{l}92.5 \pm 9.7 \\
89.2 \pm 10.3\end{array}$ & $3.301^{\mathrm{b})}$ & 0.001 \\
\hline Nursing practice ability $(\mathrm{n}=416)$ & & & $0.530^{c)}$ & 0.000 \\
\hline Job satisfaction $(\mathrm{n}=416)$ & & & $0.293^{c)}$ & 0.000 \\
\hline FSOC $(n=416)$ & & & $0.315^{c)}$ & 0.000 \\
\hline
\end{tabular}

a)Spearman's rank correlation coefficient, ${ }^{\text {b) }}$-test, ${ }^{\mathrm{c}}$ Pearson's correlation coefficient. SD: standard deviation; FSOC: Family Sense of Coherence.

Table 3. The factors associated FINC-NA: path analysis $(\mathrm{N}=349)$.

\begin{tabular}{|c|c|c|c|c|c|c|c|c|}
\hline & \multicolumn{4}{|c|}{ Nursing practice ability } & \multicolumn{4}{|c|}{ FINC-NA } \\
\hline & $\mathrm{r}$ & & $\beta$ & & $\mathrm{r}$ & & $\beta$ & \\
\hline Clinical experience & 0.167 & ** & 0.108 & & 0.021 & & -0.045 & \\
\hline Managerial experience & 0.182 & ** & 0.134 & * & 0.022 & & -0.046 & \\
\hline Family nursing experience & 0.099 & & 0.056 & & 0.110 & * & 0.045 & \\
\hline Presence of a partner & 0.089 & & -0.062 & & 0.093 & & -0.005 & \\
\hline Experience caring for own family & 0.044 & & 0.009 & & 0.026 & & 0.020 & \\
\hline Family nursing learning experience & 0.144 & ** & 0.118 & * & 0.123 & * & 0.027 & \\
\hline Job satisfaction & 0.343 & ** & 0.284 & $* *$ & 0.290 & $* *$ & 0.104 & * \\
\hline FSOC & 0.263 & ** & 0.215 & ** & 0.324 & $* *$ & 0.187 & ** \\
\hline Nursing practice ability & & & & & 0.520 & ** & 0.442 & ** \\
\hline Coefficient of determination & \multicolumn{4}{|c|}{$\mathrm{R}^{2}=0.195^{\star *}$} & \multicolumn{4}{|c|}{$\mathrm{R}^{2}=0.309^{* *}$} \\
\hline
\end{tabular}

r: Pearson's correlation coefficient, $\beta$ : standardized partial regression coefficient, FINC-NA: Families' Importance in Nursing Care-Nurses' Attitudes. ${ }^{*} \mathrm{p}<0.05,{ }^{* *} \mathrm{p}<0.01$.

who had the highest and lowest total FINC-NA scores in the residual analysis, leaving 349 nurses for analysis.

The coefficient of determination was $\mathrm{R}^{2}=0.309(\mathrm{p}<0.01)$ and the variables that affected FINC-NA were nursing practice ability $(\beta=0.442, \mathrm{p}<0.01)$, FSOC $(\beta=0.187, \mathrm{p}<0.01)$, and job satisfaction $(\beta=0.104, \mathrm{p}<0.05)$.

As a result of the path analysis with nursing practice ability as the dependent variable, job satisfaction $(\beta=0.284, \mathrm{p}<0.01)$, FSOC $(\beta=0.215, \mathrm{p}<0.01)$, managerial experience $(\beta=0.134, \mathrm{p}<0.05)$, and family nursing learning experience ( $\beta=0.118, \mathrm{p}<0.05)$ were significant. In addition, as a result of calculating the indirect effects of job satisfaction and FSOC on FINC-NA, the indirect effect 
mediated by nursing practice ability $(\beta=0.126)$ was higher than the direct effect $(\beta=0.104)$ for job satisfaction (Table 3, Figure 2).

\section{Discussion}

Based on the number of years of clinical experience or managerial experience, the participants of this study were considered proficient or expert [30]. In comparison with a previous study [25], the total FINC-NA and Fam-CP scores were almost the same, but the Fam-RNC score was slightly lower and the Fam-B score was higher. This showed that the participants did not regard the family as an important resource in nursing care, but instead felt the presence of the family to be a burden.

Sveinbjarnardottir et al. [10] showed that nurses with more than a university education do not consider patients' families to be a burden. In addition, Luttik et al. [14] reported that completing graduate school or holding the position of a researcher, educator or administrator had an effect on attitudes towards families. Comparing the present participants' characteristics with those in previous studies revealed differences in educational background or their position in the workplace. These reasons were assumed to explain the differences in the Fam-RNC and Fam-B scores.

In this study, nursing practice ability most strongly affected FINC-NA, followed by FSOC and then job satisfaction. For nurses working in medical facilities, patient care is the most important role and new nurses learn and practice patient-centered nursing from the beginning of their employment. The Scale of Nursing Practice Ability of Mid-career Nurses that was used in this study was

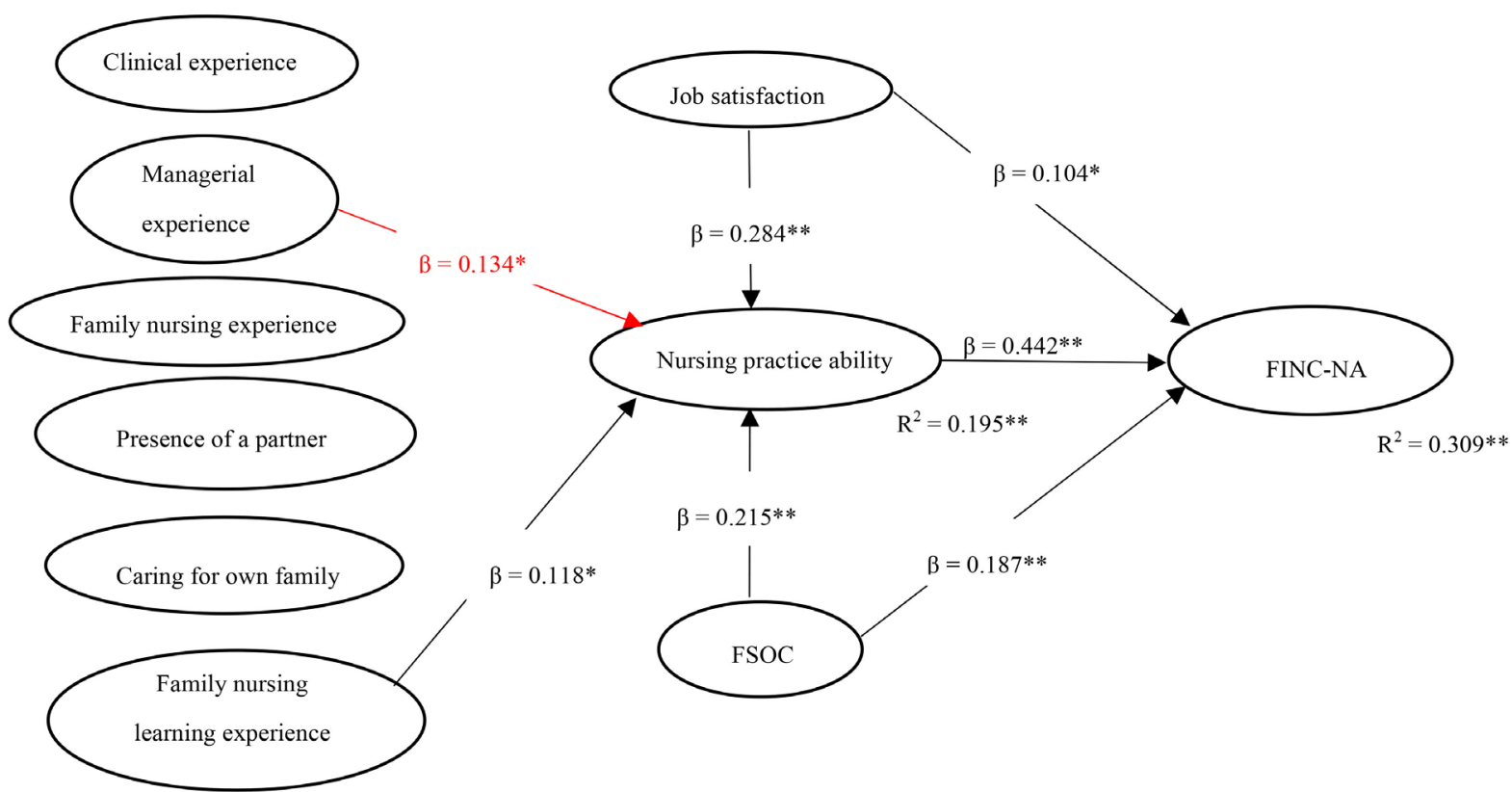

Figure 2. Results of FINC-NA path analysis. The direct effect of job satisfaction to FINC-NA: $\beta=0.104$; The indirect effect mediated by nursing practice ability: $\beta=0.284 \times 0.442=0.126$; The direct effect of FSOC to FINC-NA: $\beta=0.187$; The indirect effects mediated by nursing practice ability: $\beta=0.215 \times 0.442=0.095$. 
developed through repeated examinations and revisions of the scale. This scale contains items that whether setting goals by talking with patients and their families, and whether to evaluate patients and their families' satisfaction for practiced care. This means that mid-career nurses with high nursing practical ability can pay attention not only to patients, but also to their families, and are capable of building good relationships with them. The results of the present study supported that.

FSOC had a direct effect on nursing practice ability and on nurses' attitudes towards families. In a double ABCX model [31] used to analyze family stress in the long term, it was said that family coping became a bridging concept which had both cognitive and behavioral components wherein resources, perception, and behavioral responses interact as families try to achieve a balance in family functioning. Nurses with high FSOC scores can be regarded as having a high coping ability to balance family functions, and it was assumed that they made use of this ability to help families cope with various stresses caused by the patient's illness. Furthermore, the FSOC consists of questions about family values, such as their thoughts and the importance of family life. Since the FSOC influences nurses' attitudes towards families, it was suggested that nurses' values towards their own families affected their family nursing practice. It is important for nurses to recognize the diversity of patients' families as well as to sympathize with them, and to acknowledge their values towards their own families.

Although job satisfaction showed a direct effect on nurses' attitude towards families, the effect of nursing practice ability was stronger. Previous studies [32] [33] have shown that job satisfaction enhances the quality of care, and the same results were obtained in this study.

Managerial experience and family nursing learning experience were mentioned as factors that influence nursing practice ability. We believe that nurses with managerial experience already had high nursing practice ability, and they were further enhancing their comprehension by performing tasks such as staff coordination and family support.

In this study, nurses with family nursing learning experience had high nursing practice ability. The participants included a certain number of nurses who had learned family nursing systematically in graduate school or training. It was believed that the ability to respond to families required as nursing practical skills has been enhanced by acquiring knowledge and skills in family nursing. Furthermore, they had continued their education to improve their skills as nurses, and they were highly motivated to learn. It was considered that their willingness to learn was influenced by the acquisition of nursing practice ability.

\section{Limitations}

It is possible that attitudes and willingness to perform family nursing were higher in the participants of the present study than nurses at other facilities because the participants were recruited from medical facilities that conduct family nurs- 
ing training. Therefore, it is necessary to exercise caution when generalizing the findings of the present study.

It is necessary to consider that the answers to questions about managerial experience, family nursing experience, and family nursing learning experience showed large individual differences.

\section{Conclusion}

The factors associated with the attitudes of nurses working at medical facilities were nursing practice ability, FSOC and job satisfaction. In addition, the factors indirectly affecting attitudes through nursing practice ability were job satisfaction, FSOC, managerial experience and family nursing learning experience. It was suggested that it is possible for nurses to have a good relationship with the patient's family by looking back on and recognizing their own values in addition to acquiring skills and knowledge.

\section{Acknowledgements}

We would like to thank the participants for their cooperation. This study was supported by JSPS KAKENHI Grant Number 16H05565 (PI: A Yamazaki).

\section{Conflicts of Interest}

The authors have no conflicts of interest to disclose.

\section{References}

[1] Meiers, S.J., Tomlinson, P. and Peden-McAlpine, C. (2007) Development of the Family Nurse Caring Belief Scale (FNCBS). Journal of Family Nursing, 13, 484-502. https://doi.org/10.1177/1074840707310734

[2] Simpson, P. and Tarrant, M. (2006) Development of the Family Nursing Practice Scale. Journal of Family Nursing, 12, 413-425. https://doi.org/10.1177/1074840706290806

[3] Hallgrimsdottir, E.M. (2000) Accident and Emergency Nurses' Perceptions and Experiences of Caring for Families. Journal of Clinical Nursing, 9, 611-619. https://doi.org/10.1046/j.1365-2702.2000.00406.x

[4] Hopwood, N., Fowler, C., Lee, A., Rossiter, C. and Bigsby, M. (2013) Understanding Partnership Practice in Child and Family Nursing through the Concept of Practice Architectures. Nursing Inquiry, 20, 199-210. https://doi.org/10.1111/nin.12019

[5] Sigurdardottir, A.O., Svavarsdottir, E.K. and Juliusdottir, S. (2015) Family Nursing Hospital Training and the Outcome on Job Demands, Control and Support. Nurse Education Today, 35, 854-858. https://doi.org/10.1016/j.nedt.2015.03.003

[6] Yamazaki, A., Tsumura, A., Mine, H., Kimura, C., Soeda, A., Odatsu, K. and Kiwado, W. (2017) Feasibility and Short-Term Impact of the "Case Study in-House Group Training Program for Family Nursing” at Medical Facilities. International Journal of Nursing Practice, 23. https://doi.org/10.1111/ijn.12503

[7] Östlund, U., Bäckström, B., Lindh, V., Sundin, K. and Saveman, B.I. (2015) Nurses' Fidelity to Theory-Based Core Components When Implementing Family Health Conversations: A Qualitative Inquiry. Scandinavian Journal of Caring Sciences, 29, 
582-590. https://doi.org/10.1111/scs.12178

[8] Guest, E.M., Keatinge, D.R., Reed, J., Johnson, K.R., Higgins, H.M. and Greig, J. (2013) Implementing and Evaluating a Professional Practice Framework in Child and Family Health Nursing: A Pilot Project. Nurse Education in Practice, 13, 393-399. https://doi.org/10.1016/j.nepr.2012.11.004

[9] Linnarsson, J.R., Benzein, E. and Årestedt, K. (2015) Nurses’ Views of Forensic Care in Emergency Departments and Their Attitudes, and Involvement of Family Members. Journal of Clinical Nursing, 24, 266-274. https://doi.org/10.1111/jocn.12638

[10] Sveinbjarnardottir, E.K., Svavarsdottir, E.K. and Saveman, B.I. (2011) Nurses Attitudes towards the Importance of Families in Psychiatric Care Following an Educational and Training Intervention Program. Journal of Psychiatric \& Mental Health Nursing, 18, 895-903. https://doi.org/10.1111/j.1365-2850.2011.01744.x

[11] Gusdal, A.K., Martin, L., Josefsson, K. and Thors Adolfsson, E. (2017) Nurses' Attitudes toward Family Importance in Heart Failure Care. European Journal of Cardiovascular Nursing, 16, 256-266. https://doi.org/10.1177/1474515116687178

[12] Oliveira, R.G. and Marcon, S.S. (2007) The Opinion of Nurses Regarding the Work They Perform with Families in the Family Health Program. Revista Latino-Americana de Enfermagem ( $R L A E)$, 15, 431-438.

https://doi.org/10.1590/S0104-11692007000300011

[13] Fernandes, C.S., Pereira Gomes, J.A., Martins, M.M., Pereira Gomes, B. and Hisako Takase Gonçalves, L. (2015) The Importance of Families in Nursing Care: Nurses' Attitudes in the Hospital Environment. Revista de Enfermagem Referência, 4, 21-30. https://doi.org/10.12707/RIV15007

[14] Luttik, M.L.A., Goossens, E., Ågren, S., Jaarsma, T., Mårtensson, J., Thompson, D.R., et al. (2017) Attitudes of Nurses towards Family Involvement in the Care for Patients with Cardiovascular Diseases. European Journal of Cardiovascular Nursing, 16, 299-308. https://doi.org/10.1177/1474515116663143

[15] Basińska, M.A., Andruszkiewicz, A. and Grabowska, M. (2011) Nurses' Sense of Coherence and Their Work Related Patterns of Behavior. International Journal of Occupational Medicine and Environmental Health, 24, 256-266. https://doi.org/10.2478/s13382-011-0031-1

[16] Malinauskiene, V., Leisyte, P., Romualdas, M. and Kirtiklyte, K. (2011) Associations between Self-Rated Health and Psychosocial Conditions, Lifestyle Factors and Health Resources among Hospital Nurses in Lithuania. Journal of Advanced Nursing, 67, 2383-2393. https://doi.org/10.1111/j.1365-2648.2011.05685.x

[17] Takeuchi, T. and Yamazaki, Y. (2010) Relationship between Work-Family Conflict and a Sense of Coherence among Japanese Registered Nurses. Japan Journal of Nursing Science, 7, 158-168. https://doi.org/10.1111/j.1742-7924.2010.00154.x

[18] Fisher, C., Lindhorst, H., Matthews, T., Munroe, D.J., Paulin, D. and Scott, D. (2008) Nursing Staff Attitudes and Behaviors Regarding Family Presence in the Hospital Setting. Journal of Advanced Nursing, 64, 615-624.

https://doi.org/10.1111/j.1365-2648.2008.04828.x

[19] Benzein, E., Johansson, P., Årestedt, K.F., Berg, A. and Saveman, B.I. (2008) Families' Importance in Nursing Care-Nurses' Attitudes: An Instrument Development. Journal of Family Nursing, 14, 97-117. https://doi.org/10.1177/1074840707312716

[20] Angelo, M., Cruz, A.C., Mekitarian, F.F.P., dos Santos, C.C.D., Martinho, M. and Martins, M. (2014) Nurses' Attitudes Regarding the Importance of Families in Pediatric Nursing Care. Revista Da Escola De Enfermagem Da Usp, 48, 74-79. https://doi.org/10.1590/S0080-623420140000600011 
[21] Blöndal, K., Zoëga, S., Hafsteinsdottir, J.E., Olafsdottir, O.A., Thorvardardottir, A.B., Hafsteinsdottir, S.A. and Sveinsdóttir, H. (2014) Attitudes of Registered and Licensed Practical Nurses About the Importance of Families in Surgical Hospital Units: Findings From the Landspitali University Hospital Family Nursing Implementation Project. Journal of Family Nursing, 20, 355-375. https://doi.org/10.1177/1074840714542875

[22] Oh, J., Kim, Y.Y., Yoo, S.Y. and Cho, H. (2018) Validity and Reliability of the Korean Version of the Families' Importance in Nursing Care-Pediatric Nurses' Attitudes Instrument. Child Health Nursing Research, 24, 274-286.

https://doi.org/10.4094/chnr.2018.24.3.274

[23] Ribeiro Chaves, R.G., Macedo de Sousa, F.G., Oliveira Silva, A.C., Lopes dos Santos, G.F., Verganista Martins Fernandes, H.I. and Sampaio Cutrim, C.M. (2017) Importance of the Family in the Care Process: Attitudes of Nurses in the Context of Intensive Therapy. Journal of Nursing Universidade Federal de Pernambuco, 11, 4989-4998.

[24] Vaezi, A., Alimandegari, Z., Farnia, F. and Lotfi, M.H. (2015) The Effects of Relatives' Participation in Critical Care Delivery on Nurses' Attitude to Collaborative Care. Modern Care Journal, 12, 39-46.

[25] Watanabe, E., Matsumoto, K. and Kamibeppu, K. (2011) Development of the Japanese Version of Families' Importance in Nursing Care: Nurses' Attitudes. Oral Session Presented at 10th International Family Nursing Conference, Kyoto, Japan

[26] Sato, N., Ushida, T., Naito, R., Deguchi, S. and Tosa, C. (2007) An Attempt to Create Version 3 of the Clinical Practice Proficiency Measurement Scale for Mid-Career Nurses. The Journal of the Japan Academy of Nursing Administration and Policies, 10, 32-39

[27] Antonovsky, A. (1987) Unraveling the Mystery of Health: How People Manage Stress and Stay Well. Jossey-Bass Publishers, San Francisco, CA.

[28] Sagy, S. (1998) Effects of Personal, Family, and Community Characteristics on Emotional Reactions in a Stress Situation-The Golan Heights Negotiations. Youth \& Society, 29, 311-329. https://doi.org/10.1177/0044118X98029003003

[29] Nakayama, Y., Hori, M., Kawahara, T., Sou, H. and Yamazaki, A. (2019) Translation and Validation of the Japanese Version of the Family Sense of Coherence Scale-Short Form in Nurses. Open Journal of Nursing, 9, 901-910. https://doi.org/10.4236/ojn.2019.98067

[30] Benner, P. (1984) From Novice to Expert: Excellence and Power in Clinical Nursing. Addison-Wesley Pub. Co., Menlo Park, CA, 13-34. https://doi.org/10.1097/00000446-198412000-00027

[31] McCubbin, H.I. and Patterson, J.M. (1983) The Family Stress Process: The Double ABCX Model of Adjustment and Adaptation. Marriage \& Family Review, 6, 7-37. https://doi.org/10.1300/J002v06n01 02

[32] Gillet, N., Fouquereau, E., Coillot, H., Cougot, B., Moret, L., Dupont, S., et al. (2018) The Effects of Work Factors on Nurses' Job Satisfaction, Quality of Care and Turnover Intentions in Oncology. Journal of Advanced Nursing, 74, 1208-1219. https://doi.org/10.1111/jan.13524

[33] Leggat, S.G., Bartram, T., Casimir, G. and Stanton, P. (2010) Nurse Perceptions of the Quality of Patient Care: Confirming the Importance of Empowerment and Job Satisfaction. Health Care Management Review, 35, 355-364. https://doi.org/10.1097/HMR.0b013e3181e4ec55 